\title{
Targeting Inhaled Therapy beyond the Lungs
}

\author{
Ninell P. Mortensen ${ }^{a}$ Anthony J. Hickey ${ }^{b}$ \\ a Systems and Translational Sciences, and ${ }^{\mathrm{b}}$ Technology for Industry and the Environment, Discovery Sciences \\ Technologies Group, RTI International, Research Triangle Park, N.C., USA
}

\section{Key Words}

Aerosolization · Drug delivery · Drug release - Dissolution rate $\cdot$ Inhaled therapy $\cdot$ Systemic delivery

\begin{abstract}
Pulmonary disease has been the primary target of inhaled therapeutics for over 50 years. During that period, increasing interest has arisen in the use of this route of administration to gain access to the systemic circulation for the treatment of a number of diseases beyond the airways. In order to effectively employ this route, the barriers to transport from the lungs following deposition of aerosols must be considered, including the nature of the disease (whether proximal, as in pulmonary hypertension, or distal, as in diabetes). Delivery to the systemic circulation begins with the efficiency of aerosol generation and subsequent deposition in the airways and proceeds to the influence of mechanisms of clearance, including absorption, metabolism, and mucociliary and cellmediated transport, on the residence time of the drugs in the lungs. The nature of the drug (small or large molecules/low or high molecular weight), susceptibility to degradation and general physicochemical properties play a role in the chemistry of its formulation, physics of aerosol delivery and biology of disposition.

(c) 2014 S. Karger AG, Basel
\end{abstract}

\section{Introduction}

The recent US Food and Drug Administration approval of Afrezza [1] will increase the interest in the lung as a route for systemic administration of drugs. Moreover, it should resurrect the enthusiasm for protein and peptide delivery that fueled decades of scientific inquiry and led to many novel technologies but waned upon the withdrawal of Exubera (inhaled insulin, Pfizer) in 2007. A number of diseases with symptoms that manifest beyond the airways, including pulmonary hypertension (proximally) and migraine headaches (distally), have been the subject of recent developments [2].

In this context, a review of the considerations regarding the systemic delivery of drugs is timely. There are a number of reasons for selecting the pulmonary route of administration for systemically acting agents. These may be divided into pharmaceutical, metabolic and physiolog-

Previous articles in this series: 1. Usmani OS: New developments in inhaled drugs: within and beyond the lungs. Respiration 2014;88: 1-2. 2. Lavorini F, Fontana GA, Usmani OS: New inhaler devices the good, the bad and the ugly. Respiration 2014;88:3-15. 3. Rubin BK, Williams RW: Aerosolized antibiotics for non-cystic fibrosis bronchiectasis. Respiration 2014;88:177-184.

\section{KARGER}

E-Mail karger@karger.com

www.karger.com/res
(C) 2014 S. Karger AG, Basel

0025-7931/14/0885-0353\$39.50/0
Anthony J. Hickey

Technology for Industry and the Environment

Discovery Sciences Technologies Group, RTI International

3040 East Cornwallis Road, Research Triangle Park, NC 27709 (USA)

E-Mail ahickey@rti.org 
Fig. 1. Chemical, physical and biological considerations that define the sequence of events from product development through optimal pharmaceutical aerosol product performance to achieve the desired bioavailability and therapeutic effect.

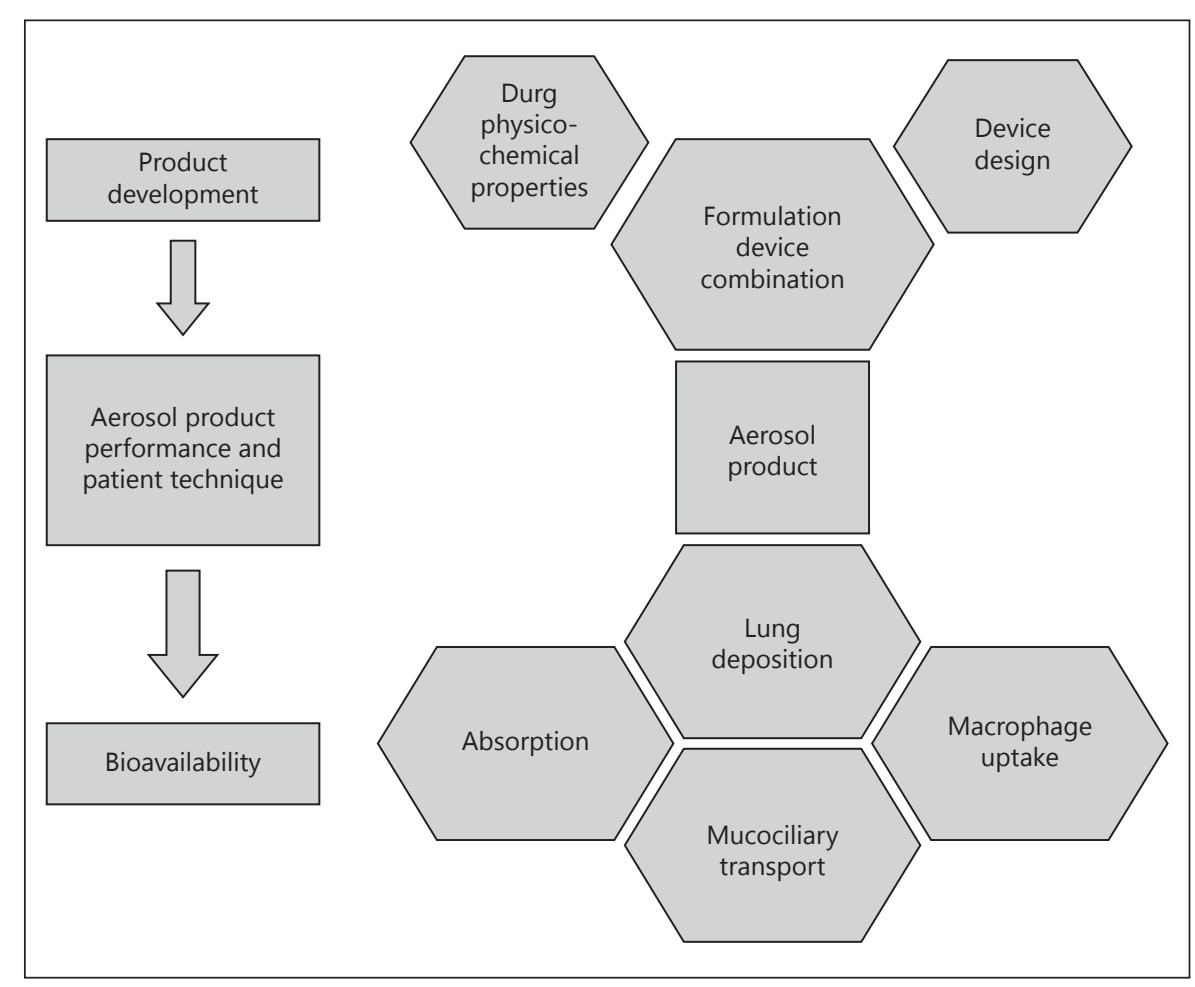

\section{Lung Physiology}

Pulmonary drug delivery for remote targeting has received less attention than local delivery to treat lung conditions such as asthma and chronic obstructive pulmonary disease. Success for examples such as inhaled administration of human growth hormone [4-6] and insulin [7-13] is a strong motivator for exploring this route of drug administration. Inhaled drug delivery can be the answer to increase bioavailability of poorly soluble drugs that have poor absorption and bioavailability in the gastrointestinal tract when orally administered or are highly metabolized by the liver. Pulmonary drug delivery bypasses the first metabolism and has the potential for reduced drug metabolism and high bioavailability. However, pulmonary drug delivery presents the challenge of reaching sufficiently high circulating drug concentrations to achieve therapeutic levels. The biology of the lungs must be taken into consideration when designing inhaled therapies, in conjunction with the physicochemical properties of the aerosolized drug particles, their disposition in the lungs and drug bioavailability. The design and technical details of the different inhalers available for pulmonary drug delivery are beyond the scope of this review, but have been extensively described elsewhere [1418]. 
Fig. 2. Schematic (a) and histopathological section (b) through the airway depicting ciliated epithelial cells [modified from 75].

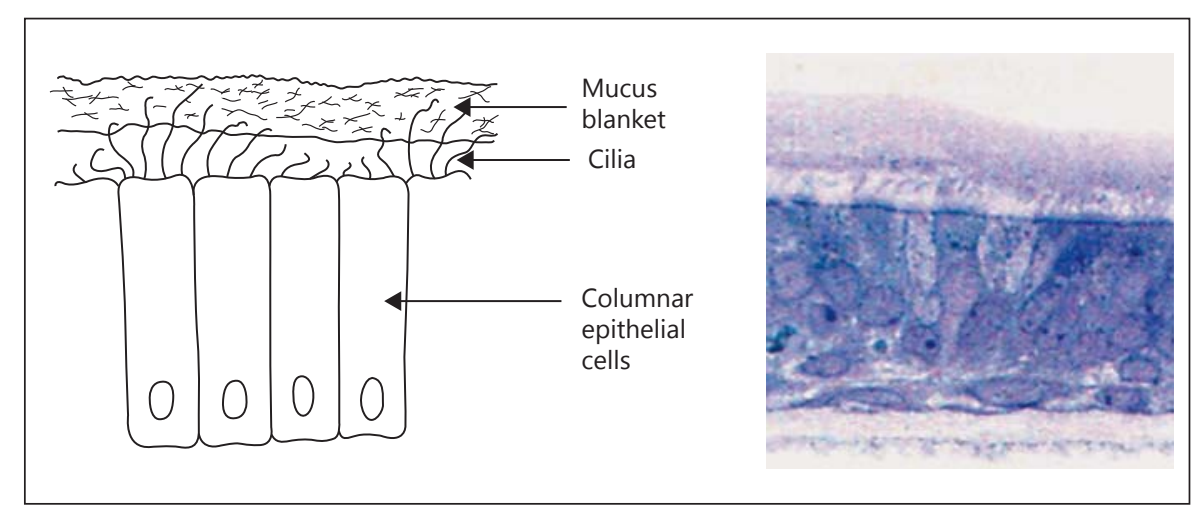

Aerosol drug delivery to the lungs generally facilitates uptake to the systemic circulation. The optimal region to target for systemic delivery is the periphery (respiratory bronchioles and alveoli) due to the large surface area, the thin epithelial barrier and close proximity to the blood and lymphatic fluid.

The human lungs divide into two functional regions, the conducting airways and the respiratory region. The conducting airways include the nasal cavity and associated sinuses, the pharynx, larynx, trachea, bronchi and bronchioles. The respiratory region is comprised of the respiratory bronchioles, the alveolar ducts and the alveolar sacs. Together the conducting airways and respiratory regions account for an estimate 23-32 branchings or generations $[15,16,19]$, and all compartments are maintained at high relative humidity, which affects the drug particle physicochemical properties as the drug particle travels though the lung. The role of humidity will be discussed later. The trachea, bronchi and bronchioles are collectively called the airways and branch off into the alveoli. In an adult, the surface area of these airways is only a few square meters in contrast to the alveolar surface area of more than $100 \mathrm{~m}^{2}$.

\section{Airways and Cells}

The drug particle traveling to the alveolar space will encounter many different cell types (epithelial, ciliated, goblet, secretory and basal cells), which are adapted to serve the specialized functions of each compartment (table 1) [16].

The major cell type of the airways is the epithelial cell, which in the bronchi of the upper airways has a columnar morphology with a height of $58 \mu \mathrm{m}$, gradually thinning in deeper portions of the lungs to a height of $0.1-0.2 \mu \mathrm{m}$
Table 1. Pulmonary cells and their function

\begin{tabular}{|c|c|}
\hline Cell & Putative function \\
\hline Ciliated columnar & Mucus movement \\
\hline Mucus (goblet) & Mucus secretion \\
\hline Serous & Periciliary fluid \\
\hline $\begin{array}{l}\text { Clara (nonciliated } \\
\text { epithelial) }\end{array}$ & $\begin{array}{l}\text { Surfactant production, } \\
\text { metabolism }\end{array}$ \\
\hline Brush & $\begin{array}{l}\text { Transitional form of ciliated } \\
\text { epithelial cells }\end{array}$ \\
\hline Basal & $\begin{array}{l}\text { Progenitor for ciliated epithelial } \\
\text { and goblet cells }\end{array}$ \\
\hline Dendritic cells & Antigen-presenting cells \\
\hline Neuroendocrine & Chemoreceptor, paracrine function \\
\hline Alveolar type I & Alveolar gas exchange \\
\hline Alveolar type II & $\begin{array}{l}\text { Surfactant secretion, differentiation } \\
\text { to type I cells }\end{array}$ \\
\hline Alveolar macrophages & Pulmonary defense \\
\hline Mast & Immunoregulation \\
\hline
\end{tabular}

forming a cellular monolayer in the alveoli (fig. 2) [16]. Two important cell types overall in the lungs are mucusproducing goblet cells and ciliated cells, which together form the mucociliary escalator, the 'housekeeping' system of the upper airways. If the drug particle deposits in the airway before reaching the alveolar space, it is likely to be carried to the trachea by the mucus escalator before its drug content is released. The protected viscous mucus layer lining epithelial cells is $8 \mu \mathrm{m}$ thick in the bronchus transition through the airways into a $0.07-\mu \mathrm{m}$-thick surfactant layer in the alveoli. The mucus layer is comprised of inorganic salts, proteins, glycoproteins (mucins), lipids and water, whereas the surfactant layer contains phospholipids, cholesterol and proteins [19]. The presence and composition of this protective lining of the lungs is likely to affect both drug solubility and diffusion towards 


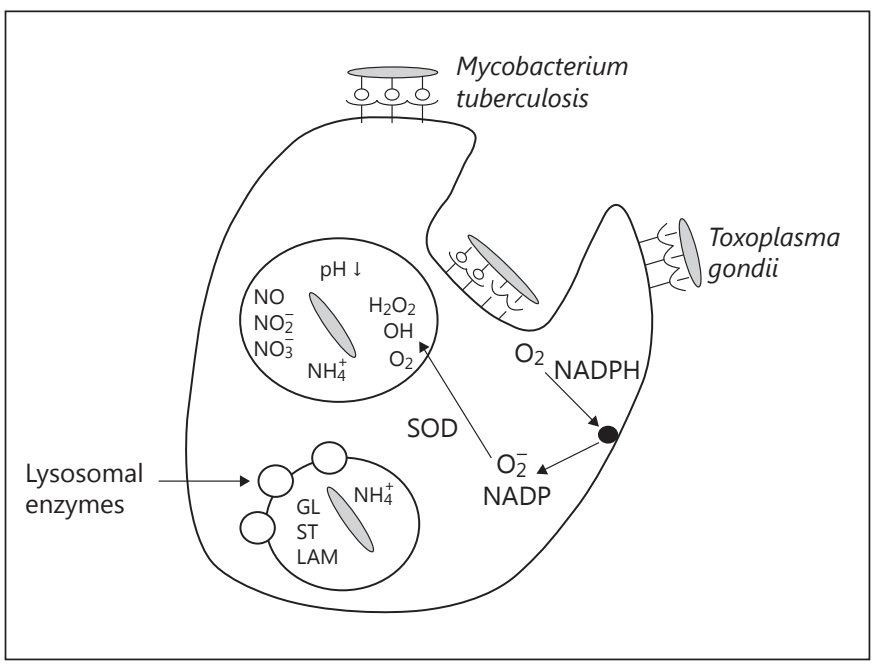

Fig. 3. Disposition of intracellular infectious microorganisms ( $M y$ cobacterium tuberculosis and Toxoplasma gondii) in alveolar macrophages

the epithelium, and the interaction between drugs and cell surfaces and receptors. Inhaled particles deposited on ciliated epithelial regions of the lungs will embed in the mucus layer, where they are transported by the ciliated cells into the esophagus, and the material is expectorated and/or swallowed. The kinetics of particle deposition, as a function of their interaction with these features of the lungs, are an important consideration for bioavailability. Mucociliary clearance rates in the absence of unique cell binding phenomena are considered to be in the 12- to 24hour range [20].

Uptake by alveolar macrophages in the periphery of the lungs is also a challenge to retaining drug particles in the lungs for sufficient time to release their contents unimpeded. Approximately $90 \%$ of alveolar macrophages are located at or near the spatial junctions between alveolar epithelial cells [21], and the air interface of each of the approximately 500 million alveoli is patrolled by $12-14$ alveolar macrophages, which phagocytose any insoluble particle that deposits in this location [22]. Delivery of drugs to the lungs can either be designed to avoid phagocytic cells or to take advantage of the phagocytic nature of the macrophages. The benefits that accrue from each of these strategies are important to the action of the drug. Avoiding macrophage uptake is important for drugs which may be subject to degradation by the enzymes in these cells, which are designed to eliminate both endogenous and exogenous substances of biological origin [23]. Conversely, it may be desirable to target macrophages as a target or a depot. Macrophages are frequently the host cells for infectious microorganisms and co-opting their phagocytic nature to deliver antibiotics allows for lower dose and more potent therapy [24, 25]. Figure 3 illustrates the sequence of events that allows two exemplary intracellular infectious microorganisms to enter the macrophage and then turn off the lysosomal antimicrobial processes and ultimately disconnect the vesicle from normal intracellular trafficking.

Pulmonary blood and lymphatic circulation are also essential features of the lungs and require consideration in respiratory drug delivery. In a normal healthy person, it is estimated that the pulmonary blood volume is approximately $10 \%$ of the total blood volume of the body, with $20-25 \%$ being arterial blood volume [26-28]. This presents the opportunity for rapidly achieving a high drug concentration in the bloodstream, but also the challenge of avoiding unintended metabolism and clearance of a drug. The entire cardiovascular output passes through the lungs, resulting in a high pulmonary blood flow, and the metabolic capacity of the lung should not be ignored [29].

\section{Transport and Metabolism}

Other biological obstacles in the fate of inhaled drug particles when they have reached the alveolar space are drug metabolism, efflux transporters (such as P-glycoprotein prominent in type I cells), protein binding and cellular permeability [19]. All metabolic enzymes found in the liver are also present in the lung, but at a lower level. For example cytochrome $\mathrm{P}_{450}$ is 5-20 times lower in the lung compared to the liver [30-34]. General metabolic enzyme and transporter pathways are illustrated in figure 4 .

\section{Transporters}

Other protein transporters such as breast cancer resistance protein, multidrug resistance-associated protein and lung resistance protein are found in the lungs and are responsible for the efflux transport of many drugs, which leads to lower absorption and bioavailability than expected [19]. All the listed biological functions are likely to differ between the various compartments of the lungs and need to be considered when designing inhaled therapies. Many aspects of pulmonary drug metabolism are not well understood at present. Also, as a combined entity, all the above biological functions will influence the rate and extent of drug absorption and retention in the lungs, which determine the bioavailability of the drug. Where under- 
Fig. 4. General metabolic pathways and the role of efflux transporters. Courtesy of Matt Redinbo, University of North Carolina at Chapel Hill.

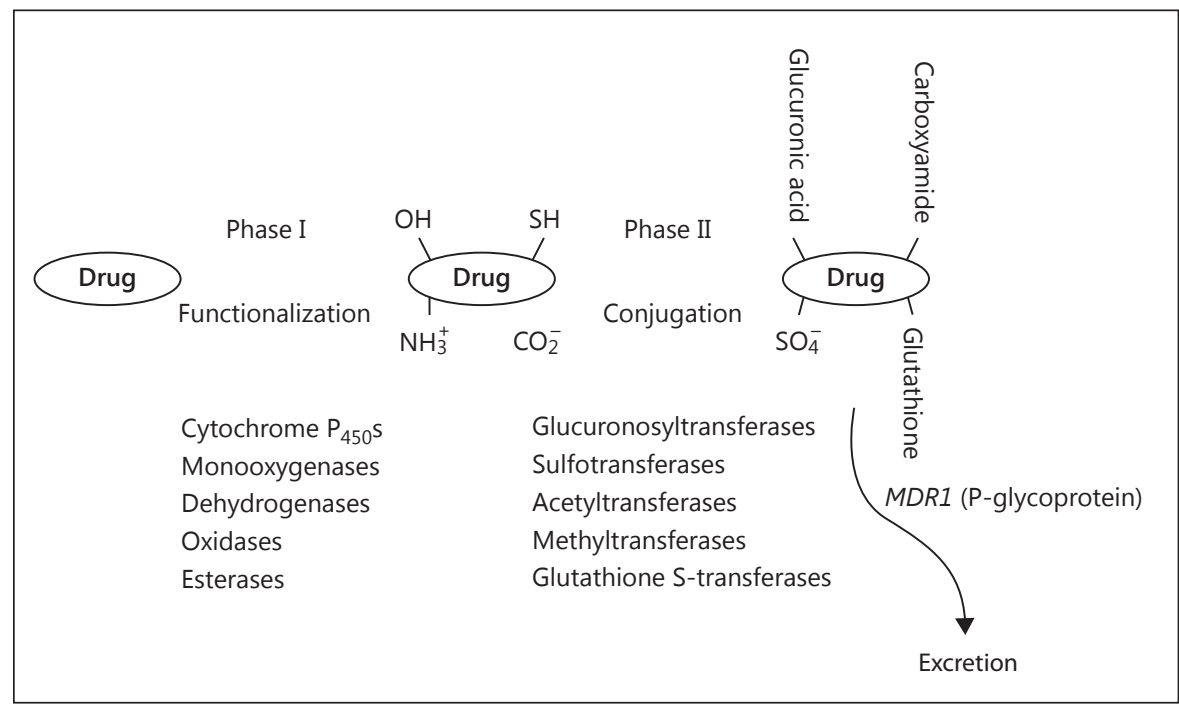

Table 2. Phase I metabolic enzymes and their appearance in the lungs [abstracted from 76]

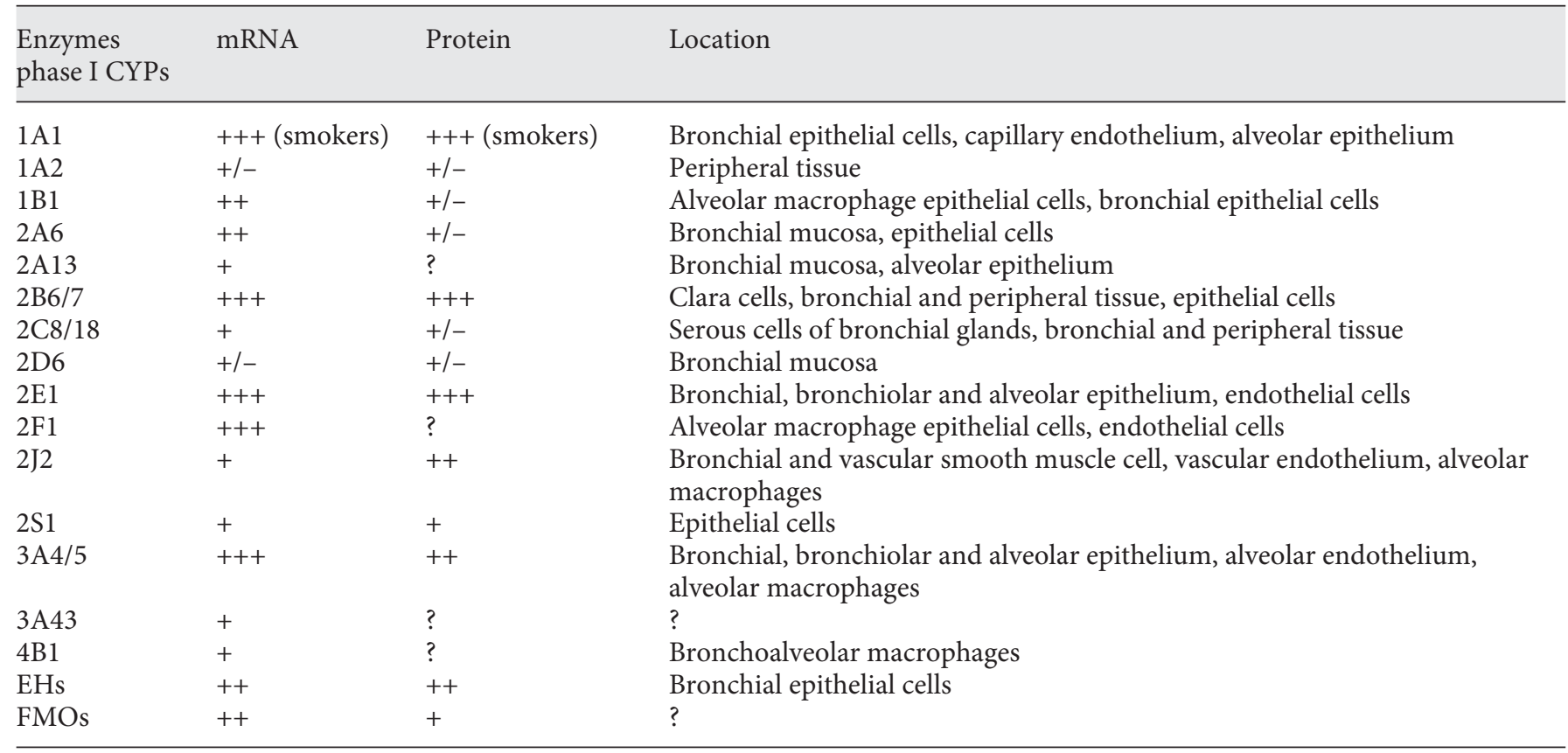

standing the pulmonary drug metabolism comes in, is that the feasible amount of material delivered to the lungs is about 100-150 mg per dose [35], which is in contrast to the gastrointestinal tract, where several grams can be easily administered. Thus, in the presence of a lower level of metabolic enzymes, efflux transporters can still have a significant impact on pulmonary drug delivery compared to the gastrointestinal tract.

Targeting Inhaled Therapy beyond the Lungs

\section{Metabolism}

Lung metabolism for small natural peptides can be very significant unless they are chemically engineered to inhibit peptidases. Besides the phase I enzymes discussed above, phase II enzymes such as uridine glucuronosyltransferase, sulfotransferase, glutathione S-transferase and peptidase activity have also been reported [36-40]. Somers et al. [34] compared the catalytic activity of both 
Table 3. Phase II metabolic enzymes and their appearance in the lungs [abstracted from 76]

\begin{tabular}{llll}
\hline Enzymes phase II & mRNA & Protein & Location \\
\hline UGT & $+/-$ & $+/-$ & Lung tissue \\
GST & & & \\
A1 & ++ & + & Bronchial and bronchiolar epithelium \\
A2 & ++ & + & Bronchial and bronchiolar epithelium \\
M1 & ++ & + & Lung tissue \\
M2 & ++ & + & Epithelium of the terminal airways \\
M3 & ++ & + & Ciliated airway epithelium and smooth muscle \\
P1 & ++ & + & Bronchial and bronchiolar epithelium \\
NAT & + & + & Bronchial epithelial cells, alveolar lining cells \\
SULT & & & \\
1A1 & + & + & Bronchial epithelial cells \\
2B1b & + & + & Bronchial epithelial cells \\
\hline
\end{tabular}

UGT = Uridine glucuronosyltransferase; GST = glutathione S-transferase; NAT = Nacetyltransferase; SULT $=$ sulfotransferase. phase I and II enzymes in isolated human lung parenchymal and hepatocyte cells using liquid chromatographytandem mass spectrometry and found that some evidence for substantial sulfation and deesterification capacity in lung parenchymal cells. Transcript profiling of xenobiotic-metabolizing enzymes encoding genes of nontumoral and tumoral lung tissue from patients with non-small lung cancer also showed the activity of several phase I and II enzymes, and, furthermore, stressed the differences in pulmonary metabolism caused by disease [40]. Tables 2 and 3 illustrate the metabolic enzymes which may be found in the lungs.

The location of enzymes within the airways and in subcellular organelles may also play a role in disposition since the route that the drug takes from the lungs will have both a spatial and temporal probability of passing through regions of high metabolic activity. Certain cells are known to be highly metabolic, such as Clara cells in the airways. Type II alveolar epithelial cells express enzymes required for metabolism, such as cytochrome $\mathrm{P}_{450}$, but type I cells are thought to have little capacity for metabolism. Enzymes are distributed in many subcellular compartments but not uniformly, as shown in table 4 .

General biochemical principles apply to the transport of molecules through or between cells, as illustrated in figure 5. Molecular and peptide absorbance kinetics in the pulmonary space can also be significantly influenced by naturally occurring glycosylation [7]. A study of $a_{1^{-}}$ antitrypsin showed a fourfold lower $t_{\max }$ if the molecule was naturally glycosylated compared to nonglycosylated molecules [7].

\section{Physical and Biological Barriers}

Physical properties of a particle, such as particle size, aerodynamic particle size distribution, mass median aerodynamic diameter $\left(d_{a}\right)$, mass distribution, shape and electrostatic charge, play an important role where the drug particles deposit in the lung. Also, the pharmacokinetic properties of drug release, which are influenced by solubility and dissolution rate, from particles and drug half-life are important factors to take into consideration for achieving a therapeutic concentration.

Pulmonary delivery of nanomedicine has to be designed to deliver the aerosolized drug particle to the intended area of the lung; the deposition is primarily based on particle size. Particle deposition occurs by inertial impaction, sedimentation, diffusion, interception and by electrostatic precipitation $[15,16,41]$. When the particle has sufficient momentum to follow its initial trajectory despite changes in the airstream, inertial impaction occurs, and the particle collides with the airway wall, often at or near a bifurcation in the lungs. Gravity also influences the particle route in the airways and in a time-dependent manner causes sedimentation. Particles small enough to be subject to random motions are subject to diffusion. Impaction and sedimentation are the dominant mechanisms of deposition of therapeutic aerosols.

The equivalent aerodynamic $\left(d_{a}\right)$ and volume diameters of a particle are the most appropriate descriptors for aerosolized drug particles. The former is particularly important as lung deposition relates to particle aerodynamic behavior. For inhalation therapy, the optimal $d_{a}$ for a particle is approximately $1-5 \mu \mathrm{m}$ [42]. Particles larger 
Table 4. Distribution of enzymes in subcellular compartments and their function [modified from 76]

\begin{tabular}{|c|c|c|c|}
\hline Localization & Phase & Enzyme & Reaction \\
\hline Cutosol & $\begin{array}{l}\text { I } \\
\text { I } \\
\text { I } \\
\text { I } \\
\text { I } \\
\text { I } \\
\text { I } \\
\text { I } \\
\text { I } \\
\text { I } \\
\text { II } \\
\text { II } \\
\text { II } \\
\text { II }\end{array}$ & $\begin{array}{l}\text { Estarase } \\
\text { Epoxide hydrolase } \\
\text { Azo and nitro reduction } \\
\text { Carbonyl reduction } \\
\text { Disulfide reduction } \\
\text { Sulfoxide reduction } \\
\text { Quinone reduction } \\
\text { Alcohol dehydrogenase } \\
\text { Aldehyde oxidase } \\
\text { Diamine oxidase } \\
\text { Sulfate conjugation } \\
\text { Glutathione conjugation } \\
\text { Acylation } \\
\text { Methylation }\end{array}$ & $\begin{array}{l}\text { Hydrolysis } \\
\text { Hydrolysis } \\
\text { Hydrolysis } \\
\text { Hydrolysis } \\
\text { Reduction } \\
\text { Reduction } \\
\text { Reduction } \\
\text { Reduction } \\
\text { Reduction } \\
\text { Oxidation }\end{array}$ \\
\hline Microsomes & $\begin{array}{l}\text { I } \\
\text { I } \\
\text { I } \\
\text { I } \\
\text { I } \\
\text { I } \\
\text { I } \\
\text { I } \\
\text { I } \\
\text { II } \\
\text { II } \\
\text { II } \\
\text { II }\end{array}$ & $\begin{array}{l}\text { Estarase } \\
\text { Epoxide hydrolase } \\
\text { Azo and nitro reduction } \\
\text { Carbonyl reduction } \\
\text { Quinone reduction } \\
\text { Reductive dehalogenation } \\
\text { Prostaglandin H synthase } \\
\text { Flavin-monooxygenases } \\
\text { Cytochrome } \mathrm{P}_{450} \\
\text { Glucuronide conjugation } \\
\text { Glutathione conjugation } \\
\text { Amino acid conjugation } \\
\text { Methylation }\end{array}$ & $\begin{array}{l}\text { Hydrolysis } \\
\text { Hydrolysis } \\
\text { Hydrolysis } \\
\text { Hydrolysis } \\
\text { Reduction } \\
\text { Reduction } \\
\text { Reduction } \\
\text { Reduction } \\
\text { Reduction }\end{array}$ \\
\hline Lysosomes & $\begin{array}{l}\mathrm{I} \\
\mathrm{I}\end{array}$ & $\begin{array}{l}\text { Estarase } \\
\text { Peptidase }\end{array}$ & $\begin{array}{l}\text { Hydrolysis } \\
\text { Hydrolysis }\end{array}$ \\
\hline Mitochondria & $\begin{array}{l}\text { I } \\
\text { I } \\
\text { II } \\
\text { II }\end{array}$ & $\begin{array}{l}\text { Alcohol dehydrogenase } \\
\text { Xanthine oxidase } \\
\text { Amino acid conjugation } \\
\text { Acylation }\end{array}$ & $\begin{array}{l}\text { Reduction } \\
\text { Reduction }\end{array}$ \\
\hline Blood & $\begin{array}{l}\text { I } \\
\text { I } \\
\text { I } \\
\text { II }\end{array}$ & $\begin{array}{l}\text { Estarase } \\
\text { Peptidase } \\
\text { Carbonyl reduction } \\
\text { Methylation }\end{array}$ & $\begin{array}{l}\text { Hydrolysis } \\
\text { Hydrolysis } \\
\text { Hydrolysis }\end{array}$ \\
\hline Microflora & 1 & Azo and nitro reduction & Hydrolysis \\
\hline
\end{tabular}

than $5 \mu \mathrm{m}$ usually experience inertial impaction early in the airways and are deposited in the oral cavity and pharynx. Particles that are smaller than $0.5 \mu \mathrm{m}$ are subject to Brownian motion and settle very slowly, and they are often exhaled before settling occurs. Also influencing the aerodynamic behavior of drug particles is the shape factor, which is dependent on particle shape, surface roughness and surface area. The shape factor is defined by the ratio of the drag force of the particle to that of a sphere of equivalent volume. Consequently, the drag force will be greater on a nonspherical particle with high surface roughness when compared to a spherical particle, and, as a result, $d_{a}$ is smaller than anticipated. Creating porous particles that have a similar mass of a drug in a larger volume also increases the drag with respect to a solid particle of the same $d_{a}$ [43]. Therefore, particle shape and density can be used to manipulate the aerodynamic properties of aerosols.

The $d_{a}$ of a drug particle can be altered when entering the high relative humidity environment in the airways, and thereby drug deposition can also be altered [30]. Rarely does removal of water occur, more frequently the cause is particle acquisition, which is a function of the initial diameter, so a particle $<1 \mu \mathrm{m}$ may increase fivefold in contrast to the two- to threefold increase for a particle $>2 \mu \mathrm{m}[44]$.

The physicochemical properties of the molecule intended for delivery also play a critical role in the formulation of inhalation therapy. Crossing the airway epithelial barrier is naturally essential for the drug to enter the blood stream, and parameters such as molecular weight, lipophilicity $(\log \mathrm{P})$, solubility, pKa, protein binding, polar surface area and charge plays into that [19]. In general, lipophilic molecules cross the airway epithelium by passive transport and hydrophilic molecules via extracellular pathways. However, molecules are delivered as particles, and particles with low dissolution rate that reach the alveolar space, past the mucociliary escalator, encounter the many alveolar macrophages and are phagocytized or absorbed into the pulmonary circulation [30]. Particle surface properties, however, are of greater interest than dissolution rate in respect to disposition. Other physicochemical properties to take into account are van der Waals forces, hydrostatic interaction, mechanical interlocking, and electrostatic and capillary forces, which are important contributors to particle interactions in the lung, which influence aggregation, and particle-particle and particle-cell interactions. In pulmonary drug delivery, achieving the intended $d_{a}$ and avoiding aggregation are essential for successful therapeutic results.

As mentioned above, the human airway is coated with a protecting surfactant layer, the protein content and composition of which varies between lung compartments. As soon as they interact with protein-rich environment, particles acquire a surface protein coating or corona. The corona is dynamic following the Vroman effect, which describes how the more abundant proteins will initially form a looser associated corona, to be re- 
Fig. 5. Mechanisms of drug transport across the pulmonary epithelium.

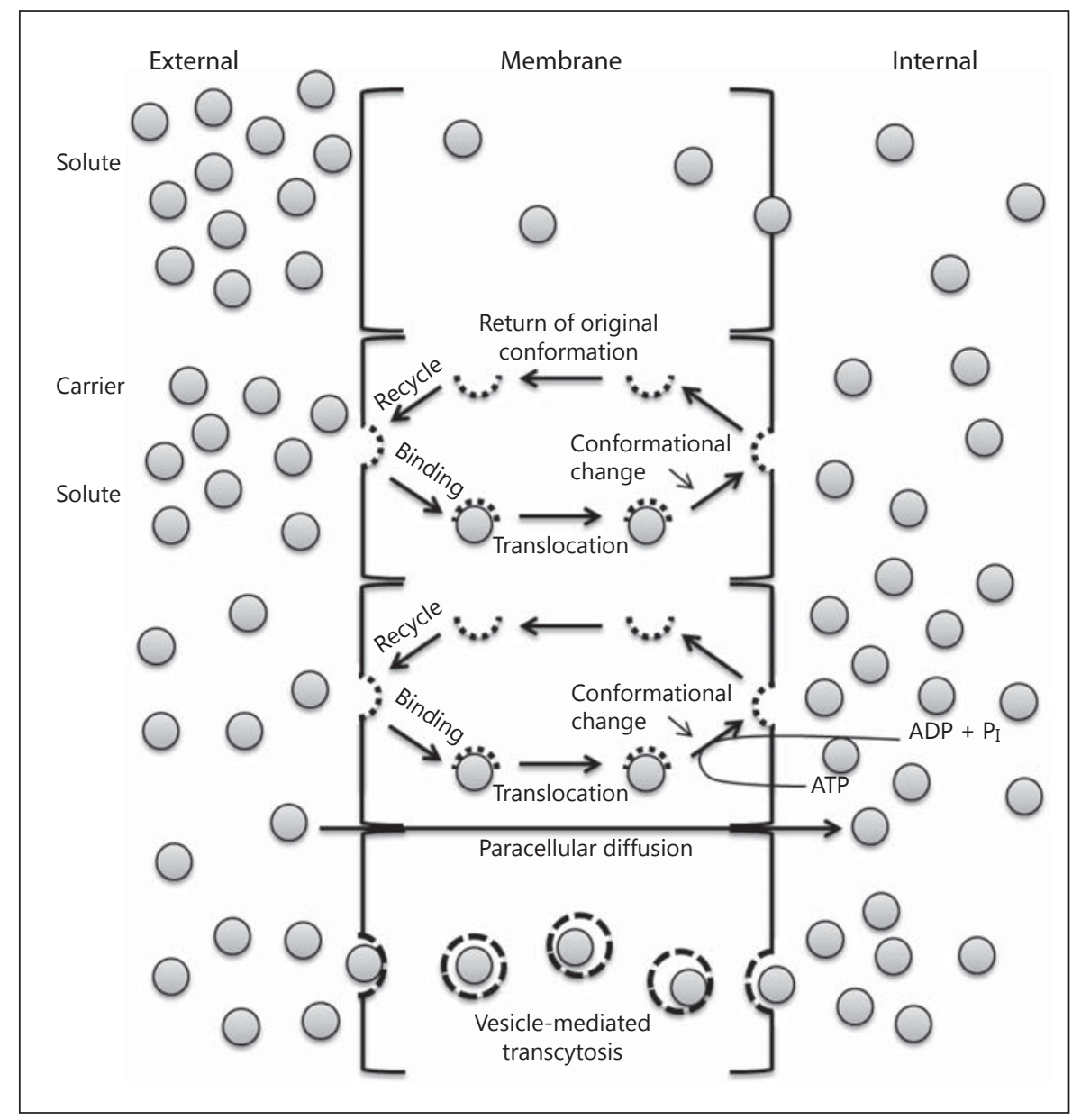

placed with less abundant proteins with higher binding affinity to the surface $[45,46]$. The protein corona composition and dynamics have been reported to be influenced by particle size, surface chemistry and charge [4750]. The protein composition might play an important role in both macrophage uptake and transport across the epithelial barrier.

\section{Fate of Microparticles and Nanoparticles}

It is important to note that lung deposition occurs most effectively for microparticles usually in the 1- to $5-\mu \mathrm{m}$ size range $[51,52]$. The recent interest in nanoparticle delivery poses some important questions considering aerosol properties. Aerosol particles or droplets are delivered as dry powders alone (via dry powder inhalers), or aqueous (nebulizers or soft mist inhalers) or nonaqueous (pressurized metered dose inhalers) suspensions or solutions [53]. Regardless of the primary particle size of the formulation (micro- or nano-sized), the particles delivered in these states from these devices are necessarily in micron sizes due to their intrinsic physicochemical properties and underlying forces of interaction. Thus, micron-sized aerosolized droplets may contain many nanoparticles that dry to form aggregates, and dry powders are dispersed as micro-agglomerated nanoparticles. Thus, conventional aerosol deposition phenomena occur, which for the size range of interest, $1-5 \mu \mathrm{m}$, for lung delivery is dominated by inertial impaction and sedimentation, as discussed earlier. It is of interest, from both safety and efficacy standpoints, to consider the extent and rate of deaggregation of nanoparticle agglomerates since this will influence a variety of elements of disposition from dissolution rate to route of elimination or access to the target site for therapy or off-target site for toxicity [54]. A micro-agglomerated nanoparticle construct may exhibit low density, in which case it may have two poten- 
tially desirable properties: the first being its small aerodynamic particle size in relation to its geometric size, which is predicted by Stokes' law [55]. In principle, the longer nanoparticles which remain aggregated are more likely to behave as microparticles with respect to clearance mechanisms. However, their low density may mean that their geometric size is too large for macrophage uptake [43]. In addition, their large surface area may increase the dissolution rate for soluble particles [55]. In turn, this will have an effect on the pharmacokinetics of drug appearance in the systemic circulation. Due to lower solubility or for other reasons, such as the presence of a hydrophobic additive, particles exhibit retarded dissolution and will retain their primary particle structure for a defined time. Assuming that deagglomeration occurs within the time frame of mucociliary clearance, intact nanoparticles will interact differently with mucus and may be retained longer than microparticles by penetrating the mucus matrix to the epithelial surface [56]. Those particles that deposit in the periphery of the lungs will not be constrained by mucociliary clearance rates. Depending on deagglomeration rates and the intermediate size of fragments of the original particles, uptake by both alveolar and airway macrophages and dendritic cells is possible, resulting in the first contact with the primary elements of the immune system in the lungs [57]. The immune response to this exposure may dictate the safety of the proposed therapy. Certain nanoparticles may also pass directly through the epithelium, which has both safety and efficacy implications for systemic exposure depending on the time the particles take to disperse into the molecular state $[58,59]$.

The most prominent nanoparticles delivered have been macromolecules which are either proteins or nucleic acids. Since their hydrodynamic radius is of nanometer size, these are definitively in the category of nanoparticles. The importance of the molecular weight of these molecules has received considerable attention [60]. In general, clearance rates from the lung decrease with increasing molecular weight. It has been suggested that for all practical purposes with some exceptions for functionalized proteins, which may utilize active clearance pathways, the molecular weight range suitable for systemic delivery through the lungs is $5-20 \mathrm{kDa}$ [7]. Delivery of proteins and peptides may be hindered by the instability of the drug in the presence of lung lining fluid, containing peptidases and other macromolecules (glycoprotein, glycolipid), by which they are degraded or to which they bind, respectively.

Historically, the influence of molecular weight on the transport of macromolecules was studied using fluores-

Targeting Inhaled Therapy beyond the Lungs

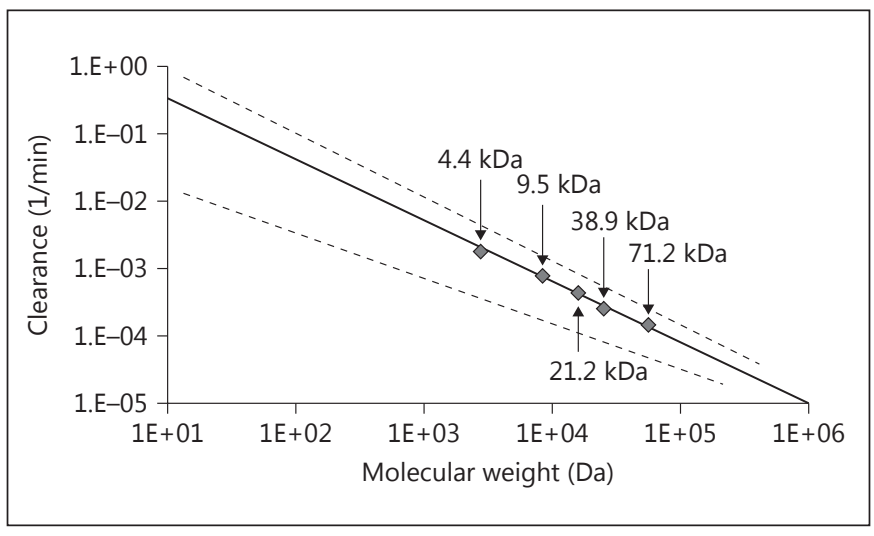

Fig. 6. Clearance as a function of molecular weight for fluorescent dextrans. The solid line depicts the mean and the dotted lines the range for data derived from a number of species including man [modified from $65,77,78]$. The data points represent data points for which permeability across small airway epithelial cells in culture demonstrated equivalence to in vivo data.

cent-labeled dextrans $[61,62]$ or other polymers [63]. Clearance has been shown to be linearly and reciprocally related to molecular weight regardless of the species [64, 65]. Figure 6 illustrates the phenomenon as observed in a cell culture model using human small airway epithelial cells onto which aerosols were sampled from an inertial impactor to achieve appropriate particle size [66].

\section{Therapeutic Examples}

A wide range of molecules have been considered for delivery to the lungs to treat a variety of systemic diseases. Interest in the lungs as a route of systemic administration existed at the onset of the biotechnology product revolution, which began in earnest in the late 1980s. In particular biological molecules that could not be delivered by the oral route and that would otherwise be injected were considered potential candidates $[67,68]$. The most prominent of these candidates were insulin for the treatment of diabetes and leuprolide acetate to treat prostate cancer $[11,69]$. Insulin posed some unique challenges in that it is required daily and with some discretion by the patient to control circulating glucose levels, but in other respects the patient may be healthy. The requirement for exquisite dose control to titrate efficacy safely resulted in the development of formulations and devices (mostly dry powder inhalers) that propelled pharmaceutical aerosol science into the 21 st century. Leuprolide acetate, a nonapeptide 
leuteinizing hormone-releasing hormone analog, was developed for the delivery in a pressurized metered dose inhaler, and as it is a relatively small peptide without secondary or tertiary structure, it did not pose such a significant formulation and stability challenge. While this product was published widely in the early 1990s, it did not proceed to the commercialization stage. A number of other proteins and peptides, including calcitonin, parathyroid hormone and growth hormone, were studied [5, 70], but none of them were commercialized.

The ability to deliver small molecular weight molecules rapidly through the lungs to relieve symptoms associated with central nervous system diseases may be traced back in modern times to a pressurized metered dose inhaler for ergotamine used to treat migraine headaches in the 1960s (3M Pharmaceuticals, St. Paul, Minn., USA) [2]. This is apparently an effective strategy since dihydroergotamine is now under development for the same purpose (Levadex; Allergan, Irvine, Calif., USA) [71]. Other agents that act in the CNS have been explored more recently, including those to treat agitation in schizophrenia (Loxapine; Alexza, Mountain View, Calif., USA) [72] and drugs used for pain relief [73].

With systemic drug delivery becoming conceptually more popular, it is not surprising that targeting a proximal site of the airways is considered. Pulmonary hypertension is a difficult disease to treat since its localization makes systemic therapy problematic. The idea of accessing the target site by direct drug delivery to the lungs is very attractive. Inhaled prostenoids have been pursued for this purpose [74].

\section{Conclusion}

The ongoing success of aerosol therapy for the treatment of pulmonary diseases has established a strong foundation for science and technology, from which to consider further applications to systemic disease, which have either proximal, e.g. in the case of pulmonary hypertension, or distal components, e.g. diabetes. Clearly, the physicochemical properties of the initial dosage form, aerosol physics leading to lung deposition and the biological barriers to presenting the drug to the circulation, all play a role in the likelihood of success in treating systemic disease. All aerosol dosage forms, e.g. pressurized metered dose inhalers, dry powder inhalers and nebulizer therapy, have the potential to deliver drugs to the lungs for systemic effects. However, macromolecules are predominantly delivered as nebulized therapy or from dry powder

inhalers. These dosage forms more readily accommodate the required doses and stability of biotechnology products. After depositing in the lungs, particles must first dissolve, and, during this period, they are being transported on the mucociliary escalator or in macrophages depending on their site of deposition and the time taken to completely convert to the molecular drug. Once dissolved, the drug will have to pass through lung lining fluid where enzyme (e.g. protease) action or binding (protein or lipid) may hinder penetration to the epithelium. Transport through or around epithelial cells may result in metabolism or transporter effects that may influence the availability of the drug in the circulation. Assuming that these potential barriers can be circumvented through judicious selection (or design) of molecules, the pulmonary route offers great potential for drugs that would otherwise be poorly bioavailable (due to their solubility or degradation in gastrointestinal fluids), toxic (due to large doses) or subject to first pass metabolism. Moreover, the pulmonary route may be considered a topical application of drugs, which does not require the invasive techniques with requisite oversight and training employed for parenteral drug administration. It may be concluded that with appropriate pharmaceutical, biological and disease state considerations, aerosol delivery of drugs to the lungs for systemic action may yet meet its full potential.

\section{Acknowledgments}

Dr. Hickey is supported in part by the National Institute of Allergy and Infectious Diseases (grant No. R01AI091882) and is principal investigator for the National Institutes of Health Nanomaterial Registry. This Registry has been funded with federal funds from the National Institute of Biomedical Imaging and Bioengineering and the following partners: the National Institute of Environmental and Health Sciences, and the National Cancer Institute, National Institutes of Health and the US Department of Health and Human Services (contract No. HHSN268201000022C).

References

Respiration 2014;88:353-364 DOI: $10.1159 / 000367852$
1 FDA: FDA approves Afrezza to treat diabetes. 2014. http://www.fda.gov/newsevents/newsroom/pressannouncements/ucm 403122 . htm.

2 Hickey AJ: Back to the future: inhaled drug products. J Pharm Sci 2013;102:1165-1172.

3 Olsson B, et al: Pulmonary drug metabolism, clearance and absorption; in Smyth HDC, Hickey AJ (eds): Controlled Pulmonary Drug Delivery. Berlin, Springer, 2012, pp 21-50.

4 Soferman R, et al: Effects of inhaled corticosteroids and inhaled cromolyn sodium on urinary growth hormone excretion in asthmatic children. Pediatr Pulmonol 1998;26:339-343. 
5 Walvoord EC, et al: Inhaled growth hormone (GH) compared with subcutaneous $\mathrm{GH}$ in children with GH deficiency: pharmacokinetics, pharmacodynamics, and safety. J Clin Endocrinol Metab 2009;94:2052-2059.

6 Nelson HS, et al: Short-term safety of somatropin inhalation powder in adults with mild to moderate asthma. Allergy Asthma Proc 2009;30:325-332.

7 Byron PR, Patton JS: Drug delivery via the respiratory tract. J Aerosol Med 1994;7:49-75.

8 Heise T, et al: PROMAXX inhaled insulin: safe and efficacious administration with a commercially available dry powder inhaler. Diabetes Obes Metab 2009;11:455-459.

-9 Mastrandrea LD: Inhaled insulin: overview of a novel route of insulin administration. Vasc Health Risk Manag 2010;6:47-58.

10 Mastrandrea LD, Quattrin T: Clinical evaluation of inhaled insulin. Adv Drug Deliv Rev 2006;58:1061-1075.

- 11 Patton JS, Bukar JG, Eldon MA: Clinical pharmacokinetics and pharmacodynamics of inhaled insulin. Clin Pharmacokinet 2004;43: 781-801.

12 White NH, et al: Efficacy and safety of inhaled human insulin (Exubera) compared to subcutaneous insulin in children ages 6 to 11 years with type 1 diabetes mellitus: results of a 3month, randomized, parallel trial. J Pediatr Endocrinol Metab 2008;21:555-568.

13 White S, et al: EXUBERA: pharmaceutical development of a novel product for pulmonary delivery of insulin. Diabetes Technol Ther 2005;7:896-906.

14 Telko MJ, Hickey AJ: Dry powder inhaler formulation. Respir Care 2005;50:1209-1227.

15 Hofmann W: Modelling inhaled particle deposition in the human lung - a review. J Aerosol Sci 2011;42:693-724.

16 Patton JS, Byron PR: Inhaling medicines: delivering drugs to the body through the lungs. Nat Rev Drug Discov 2007;6:67-74.

$\checkmark 17$ Misra A, et al: Inhaled drug therapy for treatment of tuberculosis. Tuberculosis (Edinb) 2011;91:71-81.

18 Hickey AJ, Misra A, Fourie PB: Dry powder antibiotic aerosol product development: inhaled therapy for tuberculosis. J Pharm Sci 2013;102:3900-3907.

19 Eixarch H, et al: Drug delivery to the lung: permeability and physicochemical characteristics of drugs as the basis for a pulmonary biopharmaceutical classification system (pBCS). J Epithelial Biol Pharmacol 2010;3: $1-14$.

20 Pillai G, et al: Generation of concentrated aerosols for inhalation studies. J Aerosol Sci 1994;25:10

21 Parra SC, et al: Zonal distribution of alveolar macrophages, type II pneumonocytes, and alveolar septal connective tissue gaps in adult human lungs. Am Rev Respir Dis 1986;133: 908-912.

22 Stone KC, et al: Allometric relationships of cell numbers and size in the mammalian lung. Am J Respir Cell Mol Biol 1992;6:235-243.
23 Lombry C, et al: Alveolar macrophages are a primary barrier to pulmonary absorption of macromolecules. Am J Physiol Lung Cell Mol Physiol 2004;286:L1002-L1008.

24 Suarez S, et al: Airways delivery of rifampicin microparticles for the treatment of tuberculosis. J Antimicrob Chemother 2001;48:431434.

25 Suarez S, et al: Respirable PLGA microspheres containing rifampicin for the treatment of tuberculosis: screening in an infectious disease model. Pharm Res 2001;18:1315-1319.

26 Fishman AP: The volume of blood in the lungs. Circulation 1966;33:835-838.

27 Lewis ML, et al: Determinants of pulmonary blood volume. J Clin Invest 1970;49:170-182.

28 Dock DS, et al: The pulmonary blood volume in man. J Clin Invest 1961;40:317-328.

29 Ma J, Bhat M, Rojanasakul Y: Drug metabolism and enzyme kinetics in the lung; in Hickey AJ (ed): Inhalation Aerosols. New York, Dekker, 1996.

30 Labiris NR, Dolovich MB: Pulmonary drug delivery. Part I: physiological factors affecting therapeutic effectiveness of aerosolized medications. Br J Clin Pharmacol 2003;56:588599.

31 Upton RN, Doolette DJ: Kinetic aspects of drug disposition in the lungs. Clin Exp Pharmacol Physiol 1999;26:381-391.

32 Krishna DR, Klotz U: Extrahepatic metabolism of drugs in humans. Clin Pharmacokinet 1994;26:144-160.

-33 Dahl AR, Lewis JL: Respiratory tract uptake of inhalants and metabolism of xenobiotics. Annu Rev Pharmacol Toxicol 1993;33:383407.

34 Somers GI, et al: A comparison of the expression and metabolizing activities of phase I and II enzymes in freshly isolated human lung parenchymal cells and cryopreserved human hepatocytes. Drug Metab Dispos 2007;35: 1797-1805.

35 Dharmadhikari AS, et al: Phase I, single-dose, dose-escalating study of inhaled dry powder capreomycin: a new approach to therapy of drug-resistant tuberculosis. Antimicrob Agents Chemother 2013;57:2613-2619.

36 Lorenz J, et al: Drug metabolism in man and its relationship to that in three rodent species: monooxygenase, epoxide hydrolase, and glutathione S-transferase activities in subcellular fractions of lung and liver. Biochem Med 1984;32:43-56.

37 Sidorowicz W, et al: Cleavage of the Arg1Pro2 bond of bradykinin by a human lung peptidase: isolation, characterization, and inhibition by several beta-lactam antibiotics. Proc Soc Exp Biol Med 1984;175:503-509.

38 Ekstrom L, Johansson M, Rane A: Tissue distribution and relative gene expression of UDP-glucuronosyltransferases (2B7, 2B15, 2B17) in the human fetus. Drug Metab Dispos 2013;41:291-295.
39 Kurogi K, et al: Sulfation of opioid drugs by human cytosolic sulfotransferases: metabolic labeling study and enzymatic analysis. Eur J Pharm Sci 2014;62C:40-48.

40 Leclerc J, et al: Xenobiotic metabolism and disposition in human lung: transcript profiling in non-tumoral and tumoral tissues. Biochimie 2011;93:1012-1027.

41 Carvalho TC, Peters JI, Williams RO 3rd: Influence of particle size on regional lung deposition - what evidence is there? Int J Pharm 2011;406:1-10.

42 Goodman DE, et al: The influence of age, diagnosis, and gender on proper use of metered-dose inhalers. Am J Respir Crit Care Med 1994;150:1256-1261.

43 Edwards DA, et al: Large porous particles for pulmonary drug delivery. Science 1997;276: 1868-1871.

44 Swift DL: Generation and respiratory deposition of therapeutic aerosols. Am Rev Respir Dis 1980;122:71-77.

45 Vroman L: Effect of adsorbed proteins on wettability of hydrophilic and hydrophobic solids. Nature 1962;196:476-477.

46 Vroman L, et al: Interaction of high molecular-weight kininogen, factor-XII, and fibrinogen in plasma at interfaces. Blood 1980;55: 156-159.

47 Cedervall $\mathrm{T}$, et al: Understanding the nanoparticle-protein corona using methods to quantify exchange rates and affinities of proteins for nanoparticles. Proc Natl Acad Sci USA 2007;104:2050-2055.

48 Lundqvist M, et al: Nanoparticle size and surface properties determine the protein corona with possible implications for biological impacts. Proc Natl Acad Sci USA 2008;105: 14265-14270.

49 Aggarwal P, et al: Nanoparticle interaction with plasma proteins as it relates to particle biodistribution, biocompatibility and therapeutic efficacy. Adv Drug Deliv Rev 2009;61: 428-437.

50 Mortensen NP, et al: Dynamic development of the protein corona on silica nanoparticles: composition and role in toxicity. Nanoscale 2013;5:6372-6380.

51 Hickey AJ: Summary of common approaches to pharmaceutical aerosol administration; in Hickey AJ (ed): Pharmaceutical Inhalation Aerosol Technology, ed 2. New York, Dekker, 2004.

52 Hickey AJ: Pulmonary drug delivery - pharmaceutical chemistry and aerosol technology; in Wang B, Siahaan T, Soltero RA (eds): Drug Delivery: Principles and Applications. New York, Wiley, 2004.

53 Hickey AJ: Methods of aerosol particle size characterization, in Hickey AJ (ed): Pharmaceutical Inhalation Aerosol Technology, ed 2. New York, Dekker, 2004, pp 345-384.

54 Sayes CM, Staats H, Hickey AJ: Scale of health: indices of safety and efficacy in the evolving environment of large biological datasets. Pharm Res 2014, Epub ahead of print.
Targeting Inhaled Therapy beyond the Lungs 
55 Crowder TM, et al: Fundamental effects of particle morphology on lung delivery: predictions of Stokes' law and the particular relevance to dry powder inhaler formulation and development. Pharm Res 2002;19:239-245.

56 Lai SK, Wang YY, Hanes J: Mucus-penetrating nanoparticles for drug and gene delivery to mucosal tissues. Adv Drug Deliv Rev 2009; 61:158-171.

57 Walter E, et al: Hydrophilic poly(DL-lactideco-glycolide) microspheres for the delivery of DNA to human-derived macrophages and dendritic cells. J Control Release 2001;76: 149-168.

58 Geiser M, et al: Ultrafine particles cross cellular membranes by nonphagocytic mechanisms in lungs and in cultured cells. Environ Health Perspect 2005;113:1555-1560.

59 Bharatwaj B, et al: Polymeric nanocarriers for transport modulation across the pulmonary epithelium: dendrimers, polymeric nanoparticles, and their nanoblends. AAPS J 2014; 16 : 522-538.

60 Effros RM: Solute transport following aerosol deposition in the lungs; in Hickey AJ (ed): Inhalation Aerosols: Physical and Biological Basis for Therapy. New York, Informa Healthcare, 2007, pp 127-145.

61 Effros RM, et al: Resistance of the pulmonary epithelium to movement of buffer ions. Am J Physiol Lung Cell Mol Physiol 2003;285: L476-L483.
62 Bryan R, et al: The effects of aerosolized dextran in a mouse model of Pseudomonas aeruginosa pulmonary infection. J Infect Dis 1999; 179:1449-1458.

63 Niven RW, Rypacek F, Byron PR: Solute absorption from the airways of the isolated rat lung. III. Absorption of several peptidaseresistant, synthetic polypeptides: poly-(2-hydroxyethyl)-aspartamides. Pharm Res 1990; 7:990-994.

64 Matsukawa Y, et al: Size-dependent dextran transport across rat alveolar epithelial cell monolayers. J Pharm Sci 1997;86:305-309.

65 Schanker LS, Mitchell EW, Brown RA Jr: Species comparison of drug absorption from the lung after aerosol inhalation or intratracheal injection. Drug Metab Dispos 1986;14:79-88.

66 Cooney D, Kazantseva M, Hickey AJ: Development of a size-dependent aerosol deposition model utilising human airway epithelial cells for evaluating aerosol drug delivery. Altern Lab Anim 2004;32:9.

67 Adjei AL, Gupta PK: Inhalation Delivery of Therapeutic Peptides and Proteins. New York, Dekker, 1997.

68 Patton JS, Platz RM: Routes of delivery: case studies: (2) pulmonary delivery of peptides and proteins for systemic action. Adv Drug Deliv Rev 1992;8:17.

69 Adjei A, Garren J: Pulmonary delivery of peptide drugs: effect of particle size on bioavailability of leuprolide acetate in healthy male volunteers. Pharm Res 1990;7:565-569.
70 Patton JS, Trinchero P, Platz RM: Bioavailability of pulmonary delivered peptides and proteins: interferon alpha, calcitonins and parathyroid hormones. J Control Release 1990;28:6.

71 Tepper SJ: Orally inhaled dihydroergotamine: a review. Headache 2013;53(suppl 2):43-53.

72 Currier G, Walsh P: Safety and efficacy review of inhaled loxapine for treatment of agitation. Clin Schizophr Relat Psychoses 2013;7:25-32.

$>73$ Alexander-Williams JM, Rowbotham DJ: Novel routes of opioid administration. Br J Anaesth 1998;81:3-7.

74 Gessler T, Seeger W, Schmehl T: Inhaled prostanoids in the therapy of pulmonary hypertension. J Aerosol Med Pulm Drug Deliv 2008;21:1-12.

75 Matsui H, Grubb BR, Tarran R, Randall SH, Gatzby JT, Davis CW, Boucher R: Evidence for periciliary aqueous layer depletion, not abnormal ion composition, in the pathogenesis of cystic fibrosis airways disease. Cell 1998; 95: 1005-1015.

76 Zhang JY, Wang YF, Prakash C: Xenobioticmetabolizing enzymes in human lung. Current Drug Metabolism 2006; 7:939-948.

77 Brown RP, et al: Physiological parameter values for physiologically based pharmacokinetic models. Toxicol Ind Health 1997;13:407484.

78 Klaassen CD: Casarett \& Doull's Toxicology: The Basic Science of Poisons, ed 6. New York, McGraw Hill, 2001. 